\title{
IMS Announces Winner of 2016 IMS Buehler Technical Paper Award
}

C Springer Science+Business Media, LLC and ASM International 2017

The 2016 winner of the Buehler Technical Paper Merit Award for Excellence, sponsored by Buehler, is "Quantification of Dendritic Austenite After Interrupted Solidification in a Hypoeutectic Lamellar Graphite Iron" by Björn Domeij, Juan Carlos Hernando, and Attila Diószegi. The article was published in the February 2016 issue of Metallography, Microstructure, and Analysis. The award includes a plaque and a cash prize of $\$ 1000$, endowed by Buehler. It will be presented at the ASM Leadership Awards Luncheon on Monday, October 9, 2017, in Pittsburgh, PA.

The Buehler Best Paper is chosen by the Buehler Best Paper Award Committee. The committee of judges was led by Dr. Mike Keeble, chair, and included Judy Arner, Lisa Deibler, Gabe Lucas, and Tom Murphy. The committee based their selection on several criteria. To be considered for the award, excellent specimen preparation is an essential prerequisite. Microstructural analysis, preferably by light optical microscopy or SEM, must constitute a significant portion of the paper. The paper should make use of metallographic preparation and analysis to solve a problem. The photomicrographs must be of the highest quality showing no scratches, smearing, rounding, comet tails, or other forms of preparation induced artifacts. The micrographs must aid in the understanding of the paper topic.

Congratulations are extended to the authors from the Metallography, Microstructure, and Analysis Editorial Board and the International Metallographic Society Board of Directors. 